Portland State University

PDXScholar

7-2020

\title{
Online Survey of Driver Comprehension of the Flashing Yellow Arrow for Right-Turn Signal Indications
}

\author{
Sirisha Kothuri \\ Portland State University, skothuri@pdx.edu \\ Christopher Monsere \\ Portland State University, monsere@pdx.edu \\ Hisham Jashami \\ Oregon State University \\ David Hurwitz \\ Oregon State University
}

Follow this and additional works at: https://pdxscholar.library.pdx.edu/cengin_fac

Part of the Transportation Engineering Commons

Let us know how access to this document benefits you.

\section{Citation Details}

Kothuri, S., Monsere, C., Jashami, H., \& Hurwitz, D. S. (2020). Online Survey of Driver Comprehension of the Flashing Yellow Arrow for Right-Turn Signal Indications. Journal of Transportation Engineering, Part A: Systems, 146(7), 04020058.

This Post-Print is brought to you for free and open access. It has been accepted for inclusion in Civil and Environmental Engineering Faculty Publications and Presentations by an authorized administrator of PDXScholar. Please contact us if we can make this document more accessible: pdxscholar@pdx.edu. 


\section{An Online Survey of Driver Comprehension of the Flashing Yellow Arrow for}

2 Right-Turn Signal Indications

3 Sirisha Kothuri, Ph.D.

$4 \quad$ Senior Research Associate

5 Department of Civil and Environmental Engineering

6 Portland State University

7 P.O. Box 751

8 Portland, OR 97207-0751

9 Email: $\underline{\text { skothuri@pdx.edu }}$

10 ORCID: 0000-0002-2952-169X

Christopher Monsere, Ph.D., P.E. M. ASCE (Corresponding Author)

Professor and Chair

Department of Civil and Environmental Engineering

Portland State University

P.O. Box 751

Portland, OR 97207-0751

Tel: 503-725-9746; Email: monsere@pdx.edu

ORCID: 0000-0002-9044-307X

Hisham Jashami

Graduate Research Assistant

Oregon State University

School of Civil and Construction Engineering,

101 Kearney Hall, 1491 SW Campus Way, Corvallis, OR, USA 97331

Email:jashamih@oregonstate.edu.

ORCID: 0000-0002-5511-7543

David S. Hurwitz, Ph.D. M. ASCE

Associate Professor and Eric H.I and Janice Hoffman Faculty Scholar

Oregon State University

School of Civil and Construction Engineering

101 Kearney Hall, 1491 SW Campus Way, Corvallis, OR, USA 97331

Email: david.hurwitz@ oregonstate.edu

ORCID: 0000-0001-8450-6516

40 First Submission Date: June 27, 2019

41 Revised Submission Date: October 29, 2019 
42 An Online Survey of Driver Comprehension of the Flashing Yellow Arrow for Right-Turn 43 Signal Indications

\section{ABSTRACT}

46 This paper presents the results of an online survey of licensed driver's comprehension of the right

47 turn signal displays with a focus on the flashing yellow arrow (FYA) and also including the circular green and red and red arrow. Recruitment postcards were mailed to a random sample of 9,872

49 residents in Oregon. The online survey yielded 399 responses. The open-ended responses were 50 coded for comprehension and analyzed. The results suggest that FYA for right turns is well 51 understood by Oregon drivers despite its current novelty (only two locations at the time of the 52 research). Importantly, survey respondents were more likely to recognize the yielding requirement 53 of the permissive movement and associate the yielding with pedestrians with the FYA over the 54 CG display. The research also confirmed that the expected driver response to the red arrow display 55 for right-turns is not well understood (only $52 \%$ of the respondents correctly stated the expected 56 driver response). Binary logistic regression modeling revealed that the driver's age and their 57 educational level were significant factors in comprehension. 


\section{INTRODUCTION}

The design of phasing schemes at multimodal signalized intersections are complex, multifaceted transportation engineering problems. Providing permissive turn phasing generally decreases the delay for motor vehicle traffic but can decrease the safety for other users as turning vehicles are the primary collision risk for non-motorized users. When turning movements need to be controlled or managed, proper driver response to the traffic control is critical. There is general understanding that drivers better understand the yielding required of permissive left turns when the flashing yellow arrow (FYA) is used as the display. Although FYA for right-turn arrows has been allowed by the MUTCD since the introduction of the display, there is little published research on either driver comprehension or behavioral responses in this context.

This paper presents the results of an online survey of licensed drivers that explored driver comprehension of FYA for right turn displays. Driver comprehension of other displays for rightturns (the circular green (CG) and red (CR) and the red arrow displays (RA)) was also explored. Respondents to the online survey were recruited by postcards sent to residents of the state of Oregon. A brief background of relevant research is presented in the next section, followed by a description of the survey methods and data. The results are presented, which are then discussed.

\section{BACKGROUND}

Previous research has assessed driver comprehension of signal display indications in two ways - using survey-based methods and conducting driving simulator studies. Table 1 presents a summary of the relevant research studies, including their objective, methods and key conclusions. A review of the literature found one prior work that has evaluated driver comprehension of the FYA for right-turns. Ryan et al. studied the effectiveness of flashing yellow arrows for right turn applications using a large scale static evaluation and driver simulator study (Ryan et al. 2019). 
84 Over 200 respondents participated in their static evaluation, and 24 participants undertook the 85 driver simulator exercise. Their results revealed that drivers understood the meaning of FYA and 86 exhibited safe behavior when they encountered the FYA indication during the simulator study. Of 87 the studies that have utilized surveys to understand drivers' comprehension of signal displays, the majority explored PPLT phasing (Asante and Williams, 1993; Bonneson, 1993; Noyce and Kacir,

89 2001; Drakopoulos and Lyles, 2001; Brehmer et al. 2003; Noyce and Smith, 2003; Knodler et al. 2005, 2006a, 2006b, 2007; Henery and Geyer, 2008; Schlattler et al. 2013). Only a recent study

91 by Boot et al. (2015) evaluated driver comprehension for a new flashing pedestrian indicator. All 92 of studies that used surveys were either administered as independent static evaluations or as a 93 follow-up for drivers who had completed driving simulator experiments. Most of these surveys 94 were computer-based and consisted of static images of intersections with combinations of various 95 signal displays. The questions were usually presented as multiple-choice options. The sample size 96 in these surveys varied significantly from 2,465 drivers (Noyce and Kacir, 2001) to 34 drivers 97 (Noyce and Smith, 2003), with most of the responses between 100-300 for each alternative 98 explored. comprehension of the yielding requirement of the permissive turn and found fewer fail critical 101 responses when compared to the alternatives of the CG or flashing CR or CY displays. The fivesection cluster display resulted in the lowest comprehension rates as compared to other horizontal and vertical configurations, and older drivers had lower comprehension rates for permitted leftturn displays. Two of the studies (Henery and Geyer, 2008; Schlattler et al. 2013) found that the 105 addition of supplemental signs with traffic signal increased comprehension measured in the survey. 
However, since the supplemental sign contained the desired response to the signal indication, it may have biased the results.

\section{DATA AND METHODS}

An online survey was developed to obtain both open-ended and multiple-choice responses to questions about traffic signal displays for right-turns. The survey, distribution methods, and records handling were reviewed and approved by Portland State University's IRB (163752 IR). The survey consisted of 21 questions. All survey questions were presented neutrally to allow respondents to provide meaningful positive or negative answers regarding their comprehension of the signal display indication. Past questions on other surveys of FYA comprehension and other displays were used as a guide (Knodler 2006, Boot et al. 2015). The first section of the survey included open-ended questions, which asked respondents to report their understanding of right turn signal display indications with specific questions on the comprehension of circular green (CG), green arrow (GA), circular red (CR), red arrow (RA), and flashing yellow arrow for right turns (FYART) indications. The question for each display was phrased:

"Imagine that you are approaching the intersection in the lane farthest to the right and planning to TURN RIGHT. What action would you take based on the current signal display? Please type your response in the box below and be as descriptive as possible". In these questions, respondents have presented a computer image of an intersection from a driver's perspective and instructed to assume that they were turning right. The survey used computergenerated images of an intersection with a dedicated right-turn lane similar to Boot et al. (2015).

The use of computer-generated images was chosen to control the other objects in the scene that might influencing comprehension (e.g. pedestrians) and to remove any location-specific bias. In constructing the image, the scale of the signal heads was slightly enlarged to make the displays 
more prominent in the image. In the survey, the FYA display image was animated and flashed approximately once per second. While no pedestrian is present at the near-side quadrant, one was visible on the far side of the intersection. Two versions of intersection images were developed: one with a right turn only sign (RTO) and the other without. The images used for the steady circular green comprehension question with and without RTO are presented in Figure 1.a) and 1.b). The survey was designed such that half of the respondents were randomly administered the version with the RTO sign and the other half were administered the version without the sign.

In the second section, respondents were given a set of multiple-choice questions and asked to provide their reasoning for what they perceived as similarities or differences between 1) the CR and RA and 2) the CG and FYA signal indications. The third and final section of the survey consisted of multiple-choice demographic questions on the respondent's income and education levels, driving habits, and visual capabilities.

\section{Sampling Scheme}

A sampling scheme was designed based on the proportion of the population in each county in Oregon. Table 2 shows the scheme that was used to identify the proportion of households in each county. A sample size of 10,000 respondents was selected to generate sufficient responses for analysis, assuming a 6 to $8 \%$ response rate reported for a similar postcard / online design (Currans et al. 2015). A random sample of addresses within each county was purchased through Info USA then subjected to an address cleansing process during which incorrect/missing addresses were discarded from the sample. This procedure resulted in a final sample size of 9,874 households, to which recruitment materials were sent.

\section{Recruitment Strategies}


151 A recruitment postcard containing pertinent information about the survey objectives that included

152 the online link was sent to each respondent. The postcard invited participants to take part in a 153 driver comprehension study for the Oregon Department of Transportation on traffic signals for 154 right-turns. Each household was assigned a unique ID number, which the respondents were 155 required to enter while answering the survey. Survey responses were never linked to the names of 156 the respondents; however, the ID number was used in spatial analysis. Recipients were given the 157 option of providing their contact information at the end of the online survey to be entered into a 158 drawing for one of five $\$ 100$ gift cards to a large online retailer.

\section{Response Rates}

A total of 416 respondents clicked the online link to begin the survey, and 399 respondents

161 completed the survey. Table 2 also shows the response rate by county and the percentage of the 162 sample in the response. The overall calculated response rate was $4 \%$, though the actual rate is 163 unknown since no postcards were returned as undeliverable due to the postage option selected. 164 The county-level response rate is more varied, ranging from no responses to $10 \%$ of the postcards 165 sent. Inspection of the difference column shows that the percentage of sample response has good 166 alignment with the percentage of population with the exception of the mostly urban counties near 167 the Portland metropolitan area (Clackamas, $+3.1 \%$, Multnomah, $+7.7 \%$, Washington $-3.9 \%$, 168 Marion, -3.2\%). The spatial distribution of responses is shown in Figure 2. Overall, the sample 169 was reasonably representative of the overall Oregon population distribution). 
171

172

173

174

175

176

177

178

179

180

181

182

183

184

185

186

187

188

189

190

191

192

193

\section{RESULTS AND ANALYSIS}

Of the 399 people that responded to the survey, 397 people provided some or all of the requested demographic information. Information about the basic characteristics of the survey respondents, along with percentages for Oregon from the Census Bureau, are presented in Table 3. Older, educated white males were overrepresented as survey respondents as compared to 2010 census estimates for Oregon (U.S. Census). Survey respondents were $61 \%$ male as compared to the total population of $49 \%$. Survey respondents also skewed older than the general population, with broader representation in the 55-64 and 65+ categories. Survey respondents were 93\% white/Caucasian compared to $79 \%$ reported in the census. The U.S. Census American Community Survey (ACS) data reports that approximately 30\% of Oregonians have a Bachelor's degree or higher. In the sample, over $65 \%$ of respondents had this level of education. The ACS reports that $89.5 \%$ of residents have a high school education or higher. In our sample, $98 \%$ of the respondents had this level of education. About $71 \%$ of the survey respondents reported household incomes of less than $\$ 100,000$ which compares well to the Census data of $75 \%$.

Respondents were asked to indicate how frequently and how much they drove, how long they have held a driver's license, whether the driver's license was issued by the state of Oregon if they were color deficient and/or used corrective glasses or contacts. Table 4 shows the sample characteristics based on the responses to these questions. Respondents tended to drive multiple times in a week (97\%), and most respondents were licensed for over 10 years (96\%), with nearly all of them holding an Oregon driver's license (98\%). A total of 58\% of the respondents reported that they drove more than 10,000 miles each year. A small sample of the respondents (3\%) indicated that they were color deficient and a majority of them also indicated that they used corrective glasses or contacts for vision $(65 \%)$. 


\section{Open-Ended Question Coding}

Since the survey contained open-ended questions that were designed to assess the comprehension of various signal display indications, the responses had to be categorized for

197 further analysis. The responses were coded as correct, partially correct, or incorrect by two researchers working independently, based on criteria that were established for assessing the

199 correctness of the responses (Table 5). Interrater reliability was assessed using Cohen's kappa 200 coefficient $\mathrm{K}$, a statistic that measures interrater agreement for categorical items. This coefficient 201 is calculated as follows in equation 1.

$$
\kappa=\frac{\operatorname{Pr}(a)-\operatorname{Pr}(e)}{1-\operatorname{Pr}(e)}
$$

Where $\operatorname{Pr}(\mathrm{a})$ represents the actual observed agreement, and $\operatorname{Pr}(\mathrm{e})$ represents the chance agreement. $\operatorname{Pr}(\mathrm{e})$ is calculated using the following formula (equation 2)

Where $\mathrm{cm}^{1}$ is column 1 total, $\mathrm{cm}^{2}$ is column 2 total, $\mathrm{rm}^{1}$ is row 1 total, $\mathrm{rm}^{2}$ represents row 2 total, and $\mathrm{n}$ is the number of observations.

This statistic can range between -1 and +1 , where 0 represents the amount of agreement that is due to random chance, and 1 represents a perfect agreement between the raters (McHugh 2012). Kappa statistic values between 0.61-0.80 indicate substantial agreement, and those between 0.81-1.00 represent almost perfect agreement. The Cohen's kappa statistic was calculated for the steady circular green, steady green arrow, steady circular red, steady red arrow, and flashing yellow

213 arrow questions separately for with and without the "Right Turn Only" sign responses. Table 6 214 shows the estimated values of the kappa statistic for each of the trials. For all questions except the 215 green arrow, one independent coding trial was conducted and the kappa values are shown in Table 
217 kappa statistic (trials 1 and 2), the entire research team met to discuss and resolve the coding

218 discrepancies by arriving at a shared consensus for all responses.

219 Comprehension Rates

220 Survey respondents were asked to imagine themselves as a driver in the right lane and

221 asked to describe their resulting course of action when faced with the following display indications

222 - steady green circular ball (CG), steady green arrow (GA), steady red circular ball (CR), steady

223 red arrow (RA), and flashing yellow arrow for right turns (FYA $\left.A_{R T}\right)$. The resulting responses for

224 each question were coded as correct, partially correct, or incorrect based on the criteria developed

225 as described earlier and shown in Table 5.

Descriptive Analysis

Table 7 presents the results of the coding exercise. Overall, 399 respondents (196 responses with RTO sign, 203 responses without sign) provided answers to questions pertaining to each of

229 the signal display indications. The table is arranged with the protected (GA) and permissive 230 displays (GA, CG, and FYA $\mathrm{RT}_{\mathrm{R}}$ ) on the top and the red displays (CR and RA) on the bottom for 231 comparison. Around $30 \%$ of the respondents did not completely state that the GA represents a 232 protected movement and that they would not need to yield to pedestrians and other vehicles. The 233 most common incorrect/missing perception was that they needed to yield to pedestrians while a 234 steady green arrow was displayed. While we coded this response as partially correct, we note that 235 this is a fail-safe response as many respondents indicated that they prefer to be cautious and check 236 for pedestrians prior to turning. Interestingly, the presence of the right-turn only sign increased the 237 correct response rate by $11 \%$ and was statistically significantly different. 

that they would turn right and yield to pedestrians in the crosswalk. However, a total of $25 \%$ of respondents stated that they had the right-of-way to proceed but did not include any descriptions 241 of yielding to pedestrians prior to turning (coded partially correct). A small proportion of 242 respondents $(2 \%)$ indicated they would stop prior to turning. Small differences were noticed 243 between responses with and without the RTO sign, with a lower proportion of drivers (69\% vs. $24476 \%$ ) indicating that they would yield to pedestrians, with the right turn only sign compared to 245 those without the right turn only sign. However, these differences were not statistically significant. 246 Similar comprehension rates were found for the FYART. A total of $76 \%$ of the respondents 247 understood the purpose of the FYART indication and stated that they would turn right after yielding 248 to any pedestrians in the crosswalk. A higher proportion of correct responses were observed when 249 the right turn only sign was present (81\%) compared to when it was absent (72\%) but was not 250 statistically significant. The primary difference between the FYART and the CG was that $20 \%$ of 251 respondents indicated that they would stop before turning. This incorrect response is a fail-safe 252 error. In other words, when presented with the FYART, respondents either stated that they 253 recognized the required yielding condition or would stop first, both responses that appear to 254 support increased pedestrian safety.

For the red displays, $83 \%$ of respondents provided the correct response to the CR indication with little difference between those viewing images with and without the right turn only sign. Of 257 the incorrect responses, the most common was some variation of "come to a stop and wait for a 258 circular green or green arrow." Legal driver response to the RA varies from state to state. In the 259 Pacific NW states of Oregon, Washington, and Idaho, vehicle codes do not differentiate between the RA and CR in expected driver response. California requires drivers faced with the RA to stop 
261 and remain stopped. In the context of Oregon vehicle codes, the RA display was incorrectly

262 interpreted by $34 \%$ of respondents with the RTO sign and $46 \%$ without the RTO sign. The most

263 common incorrect/missing response was again fail-safe, with the perception that drivers needed to

264 remain stopped until the indication changed to green. The comprehension rate was the lowest of

265 all the signal displays explored for controlling right turns.

266 Binary Logit Model

267 A logistic regression model was developed to further explore the probability of the 268 participant's correct/incorrect responses. Statistical analysis was performed using Minitab 16.2.4

269 software. The binary logistic regression technique labels the response variable with two outcomes

270 (dichotomy) that are often labeled as " 0 " and " 1 " instead of numeric. In this study, the dependent

271 variable was denoted as $\mathrm{y}=1$ for correct response and $\mathrm{y}=0$ for incorrect response. Thus, the

272 probability that a participant will respond correctly to a particular signal or not can be modeled as

273 a logistic distribution by the following form (equation 3):

$$
\log \left[\frac{p}{1-p}\right]=\alpha+\beta_{i} X_{i}
$$

275 Where $p$ is the probability that participant will respond correctly for a particular signal, $\alpha$ is the 276 intercept, and $\beta_{i}$ is the model coefficient for each independent variable $X_{i}$

To identify the participant's response to different signal indications, five binary logistic

278 regression models were developed to analyze factors that influence participant comprehension 279 response. More specifically, binary logistic regression was employed to model responses 280 (dependent variable), using signal indication characteristics, and the demographic variables 281 (independent variables) as defined in Table 2 and 3. A stepwise procedure was used to select 282 significant predictors and exclude insignificant ones from the final models. Significant variables 
283 in the final models were age, gender, miles driven per year, driving license, years holding driving

284 license, education, and sign's present. Table 8 summarizes the descriptive statistics of the 285 significant variables in the final models.

For each of the five models, the response variable was the individual response to the signal

287 type given the presented scenario. All estimated parameters included in the models were 288 statistically significant, and all signs were conceptually plausible. Additionally, most of the common variables among the five models had similar signs (i.e., variables that increased the 290 probability of responding correctly to particular signal generally increased a correct response rate 291 in other signals, and vice versa). A positive (or negative) sign for the coefficient in the models 292 suggested that an increase in this variable increased (or decreased) the probability of responding 293 correctly to the assigned question. Finally, to determine how effectively the model describes the 294 outcome variables, three different goodness-of-fit tests (Deviance, Pearson, and Hosmer295 Lemeshow) were considered. The Hosmer-Lemeshow test is more appropriate when the data is 296 formatted in a binary response (Homser and Lemeshow, 2013). If the p-value for the test is not 297 significant $(\mathrm{P}$-value $>0.05)$, this indicates that the model fits the data well. The computed P-values 298 from the chi-square distribution of the five models were insignificant (see Table 9). These values 299 imply that the binomial distributions predict the outcome variables accurately.

The odds ratio (OR) was used to determine differences in the response of the participant, either 301 comprehended the presented scenario correctly or incorrectly. The OR that is equal to $\operatorname{EXP}\left(\beta_{i}\right)$ is 302 defined as the relative amount (odds) of a participant responding correctly for a particular scenario 303 divided by the odds of a participant responding incorrectly for the same scenario. If the magnitude 304 is greater than 1, the likelihood of correct response increases when the value of the independent 305 variable is increased by 1 unit and vice versa when it is less than 1 . For categorical independent 
variables, the odds ratios represent the comparison of the correct response likelihood between

307 different levels of the factors, such as the respondent having an Oregon driving license or not.

308 Table 9 shows the binary logistic regression estimates of individual correct/incorrect responses.

309 The "-_sign indicates that this variable was not statistically significant and was therefore not 310 included in the model.

311 Older respondents are less likely to generate a correct answer from a given scenario than older 312 younger for all five indications (CG, GA, CR, RA, and FYA $\mathrm{RT})$. Participants with a high school 313 degree are less likely to respond correctly than others. Finally, if respondents drive less than 10,000 314 miles per year, they are less likely to respond to the CR scenario correctly.

315 Participants holding a driver's license for more than 10 years are more likely to respond 316 correctly to GA and CG scenarios. The presence of right turn sign tended to increase the likelihood 317 that a participant would respond correctly for FYART and RA scenarios. Male respondents are 318 twice as likely to get a correct response for the FYART scenario as are female. Additionally, Oregon 319 driver license holders are 5.39 times more likely to respond with a correct answer than others for $320 \quad$ FYART scenario.

\section{DISCUSSION}

322 This research explored Oregon driver's comprehension of various signal indications for right323 turns. Given the importance of improving pedestrian safety at intersections, it is essential to 324 understand how drivers comprehend various signal displays and the factors that significantly 325 impact the comprehension rates. The first useful observation from this research is that most 326 respondents understood FYA $\mathrm{AT}_{\mathrm{R}}$ display even though it is currently uncommon in Oregon (only two 327 known installations at the time of the survey). The stated comprehension was high, especially of 328 the yielding requirement of the permissive movement. This is most likely partially explained by 
329 Oregon driver's familiarity with the FYA displays for left turns. Oregon was an early adopter of 330 the display and implemented it for permissive left-turns as early as 2001. For the FYART the 331 incorrect responses were a fail-safe comprehension error with drivers indicating they would stop. 332 In contrast, around $25 \%$ of drivers did not include the concept of yielding when presented with the 333 CG. While these drivers would likely yield when encountering a pedestrian in actual driving, the 334 advantage of the FYA $\mathrm{RT}_{\mathrm{RT}}$ display appears to be that driver's better associate this display with 335 yielding. is a significant misunderstanding of the required driver response for the steady red arrow signal. In Oregon, the proper expected response from a driver for both displays is the same. However, it 339 is clear that many drivers expect that the arrow display is requiring a different response. A recent 340 survey of the right-turn on red arrow policies across the U.S. revealed that a majority of the states 341 (35) permitted right-turns on a red arrow, and 15 states prohibited it (Hassan, 2016). The source 342 of confusion is likely due to the different driver expectations for the same display for left and right343 turns. While drivers are expected to stop and remain stopped when faced with a red arrow for left344 turns, they are allowed to stop and proceed if they find a safe gap for right-turns in Oregon. The 345 confusion with the circular and arrow displays is similar to the different driver expectations for the 346 circular green and green arrow signal displays. The MUTCD defines the appropriate driver 347 response to the steady green arrow as identical to that of the circular green: proceed after yielding 348 to conflicting vehicles and pedestrians. However, it also forbids use of the arrow with any 349 conflicting movement, so, in practice, motor vehicles are always provided an exclusive movement with this display. However, this is not the case with the red arrow movement, where drivers are 351 expected to stop, yield to pedestrians and proceed only if a safe gap is found. 
353 sign is not easily explained. For the two statistically significant different comprehension rates (GA

354 and RA) in the descriptive comparisons, respondents presented with the sign had improved 355 comprehension rates. The logit modeling found that the presence of the right turn only sign 356 increased the likelihood of a correct response to the FYART and RA displays by 1.59 and 1.67 357 times, respectively. Henery et al. (2008) found improved comprehension with a supplemental sign 358 "Left Turn Yield on FYA" but as the RTO sign contains no additional information about responses 359 it is not clear what the mechanism for improved comprehension is. One hypothesis is that the sign 360 quickly clarifies which signal head is for right-turns and may allow for additional time to respond 361 to the question or understand the situation. However, the sign did not notably improve 362 comprehension for the other displays, and, as such, this hypothesis is weak.

The context of the survey and the age and education levels of this sample should be 364 considered in the transferability of the results to other jurisdictions. First, FYAs for left-turns have 365 been used in Oregon for nearly two decades and likely contributed to the high comprehension 366 exhibited in the survey. Second, the logistic modeling found age and education to be predictors or 367 comprehension, and our survey sample was overrepresented in these two categories. However, the 368 work by Ryan et al. (2019) also found strong comprehension and better yielding to pedestrians 369 with the FYART.

\section{CONCLUSIONS}

371 In summary, this research provided the first look at the comprehension rates of drivers with the 372 FYART display. The results obtained show high comprehension of the yielding response required 373 by the FYA indication for permitted right turns and provides support for operating FYA in 374 permitted or protected-permissive mode for right turn operations. Traffic engineers could also 
375 explore the use of the FYA $\mathrm{RT}_{\mathrm{RT}}$ when pedestrians are present, and geometry and signal operations

376 allow for a separate signal head controlling right-turning traffic. Significant confusion was

377 exhibited by drivers when faced with the red arrow display for right-turn movements. The use of

378 R10-17a "RIGHT ON RED ARROW AFTER STOP" sign at locations with red arrows for right-

379 turn indications may help alleviate the confusion. A better solution would be to pursue uniformity

380 in vehicle codes as suggested by FHWA (2001).

381 There are a few limitations to this research. As the results are based on survey data, the

382 usual limitations about the representativeness of the sample apply. Since the recruitment of the

383 subjects was via U.S. mail, it was not as representative of younger adults and skewed towards

384 white men and an older population compared to most recent Census distributions. Self-selection

385 of respondents may also skew the results towards more interested or informed drivers. Future

386 research could consider in-person intercept surveys or a hybrid postcard and social media

387 distribution campaign to improve the sample representativeness. The survey analysis was based

388 on coding the presence or absence of words in the open-ended responses. A more interactive survey

389 or focus group approach could elicit additional understanding of driver yielding comprehension.

390 Additionally, respondents in Oregon may be familiar with the law in California, where steady red

391 arrow laws require drivers to stop and remain stopped until the green indication due to travel or

392 population migration. While this study shows the results from a stated preference experiment,

393 actual driver responses may be different. In a follow-up study, however, Jashmi et al. (2019)

394 confirmed these findings in a driver simulation environment. 


\section{DATA AVAILABILITY STATEMENT}

396 Some or all data, models, or code generated or used during the study are available from the 397 corresponding author by request (de-identified survey response data, survey instrument, model 398 analysis code).

399 ACKNOWLEDGMENTS

400 This project was funded by the Oregon Department of Transportation under study number 401 SPR 789. The authors would like to recognize the contributions of time and technical expertise 402 provided by Mark Joerger, Julie Kentosh, Katie Johnson, and Scott Black with the Oregon 403 Department of Transportation (ODOT). 


\section{REFERENCES}

Asante, S.A., Ardekani, S.A., and Williams, J.C. (1993) "Selection Criteria for Left-Turn Phasing, Indication Sequence, and Auxiliary Sign.” Report 1256-1F, Civil Engineering Department, University of Texas at Arlington, Arlington, TX.

Bonneson, J.A., and McCoy, P.T. (1993). “Evaluation of Protected/Permitted Left-Turn Traffic Signal Displays." Report TRP-02-27-92. Civil Engineering Department, University of Nebraska-Lincoln, Lincoln, NE.

Boot, W., Charness, N., Roque, N., Barajas, K., Dirghalli, J., and Mitchum, A. (2015). "The Flashing Right Turn Signal with Pedestrian Indication: Human Factor Studies to Understand the Potential of a New Signal to Increase Awareness of and Attention to Crossing Pedestrians." Florida Department of Transportation.

Brehmer, C.L., Kacir, K.C., Noyce, D.A., and Manser M.P. (2003). "Evaluation of Traffic Signal Displays for Protected/Permissive Left-Turn Control." NCHRP Report 493, Transportation Research Board of the National Academies, Washington, D.C.

Currans, K., Gehrke, S., and K. Clifton. Visualizing Neighborhoods in Transportation Surveys: Testing Respondent Perceptions of Housing, Accessibility, and Transportation Characteristics. Proceedings of the $94^{\text {th }}$ Annual Meeting of the Transportation Research Board, Transportation Research Board of the National Academies, Washington DC, 2015.

Drakopoulos, A., and Lyles, R.W. (2014). "An Evaluation of Age Effects on Driver Comprehension of Flashing Traffic Signal Indications using Multivariate Multiple Response Analysis of Variance Models.” Journal of Safety Research, 32 (1), 85-106.

FHWA (2001). “MUTCD Interpretation: Right Turn on Red Arrow” No. 4-230

Hassan, S. Right Turns on Red Arrow by State Does Your State Allow It? Presented at 95th Annual Meeting of the Transportation Research Board, Washington, D.C., 2016.

Henery, S., and Geyer, R. (2008). "Assessment of Driver Recognition of Flashing Yellow Left-Turn Arrows in Missouri." Missouri Department of Transportation.

Hosmer, D. W., Jr., S. A. Lemeshow, and R. X. Sturdivant. (2013). “Applied Logistic Regression." 3rd ed. Hoboken, NJ: Wiley.

Hurwitz, D., Monsere, C., Kothuri, S., Jashami, H., Buker, K., and Kading, A. (2018). "Improved Safety and Efficiency of Protected/Permitted Right-Turns in Oregon" Report FHWA-ORRD-18-14. Oregon. Dept. of Transportation, Salem, OR.

Jashami., H., Hurwitz, D. Monsere, C., Kothuri, S. "Evaluation of Driver Comprehension and Visual Attention of the Flashing Yellow Arrow Display for Permissive Right-Turns" Transportation Research Record: Journal of the Transportation Research Board, Transportation Research Board of the National Academies, Washington, D.C., 2019. doi.org/10.1177/0361198119843093

Knodler, M.A., Noyce, D.A. Kacir, K.C., and Brehmer, C.L.(2007). “An Evaluation of Driver Comprehension of Solid Yellow Indications Resulting from Implementation of the Flashing Yellow Arrow." Transportation Research Board Annual Meeting, Paper \#072293, TRB, Washington, D.C. 
Knodler, M.A., Noyce, D.A. Kacir, K.C., and Brehmer, C.L. (2005). "Evaluation of Flashing Yellow Arrow in Traffic Signal Displays with Simultaneous Permissive Indications." Transportation Research Record: Journal of the Transportation Research Board, 1918, 46-55.

Knodler, M.A., Noyce, D.A. Kacir, K.C., and Brehmer, C.L.(2006a). "Analysis of Driver and Pedestrian Comprehension of Requirements for Permissive Left-Turn Applications." Transportation Research Record: Journal of the Transportation Research Board, 1982, 65-75.

Knodler, M.A., Noyce, D.A. Kacir, K.C., and Brehmer, C.L.(2006b)."Potential Application of Flashing Yellow Arrow Permissive Indication in Separated Left-Turn Lanes." Transportation Research Record: Journal of the Transportation Research Board, 1973, 10-17.

M.L. McHugh. 2012. "Interrater Reliability: The Kappa Statistic" Biochem Med (Zagreb). 22(3): 276-282. https://www.ncbi.nlm.nih.gov/pubmed/23092060

Noyce, D.A., and C.R. Smith. (2003). "Driving Simulators Evaluation of Novel Traffic-Control Devices: Protected-Permissive Left-Turn Signal Display Analysis." Transportation Research Record: Journal of the Transportation Research Board, 1844, 25-34.

Ryan A., E. Casola, C. Fitzpatrick, M. Knodler, (2019) "Flashing yellow arrows for right turn applications: A driving simulator study and static evaluation analysis." Transportation Research Part F: Traffic Psychology and Behaviour, Volume 66, 324-338, ISSN 13698478, https://doi.org/10.1016/j.trf.2019.09.013.

Schattler, K.L., Rietgraf, A., Burdett, B., and Lorton, W. (2013). "Driver Comprehension and Operations Evaluation of Flashing Yellow Arrows." Illinois Center for Transportation. 


\section{FIGURE CAPTION LIST}

469 Fig. 1 a). Steady Green Circular Ball Question Image (without Right Turn Only Sign). Source:

$470 \quad$ Hurwitz et al. 2018

471

472 Fig. 1 b). Steady Green Circular Ball Question Image (with Right Turn Only Sign). Source:

473 Hurwitz et al. 2018

474

475 Fig. 2. Geographic Distribution of Respondents. Source: Hurwitz et al. 2018

476 


\section{TABLE CAPTION LIST}

478 Table 1. Summary of Literature Review Findings

479 Table 2. Survey Sampling Scheme and Response Rates

480 Table 3. Demographic Comparison between Survey and Census

481 Table 4. Sample Characteristics

482 Table 5. Error Coding of Narrative

483 Table 6. Cohen's Kappa Coefficient Estimated Values

484 Table 7. Comprehension Rates

485 Table 8. Definitions and summary statistics of significant variables in final models

486 Table 9. Parameter estimates of the logistic regression model for correct/incorrect response 


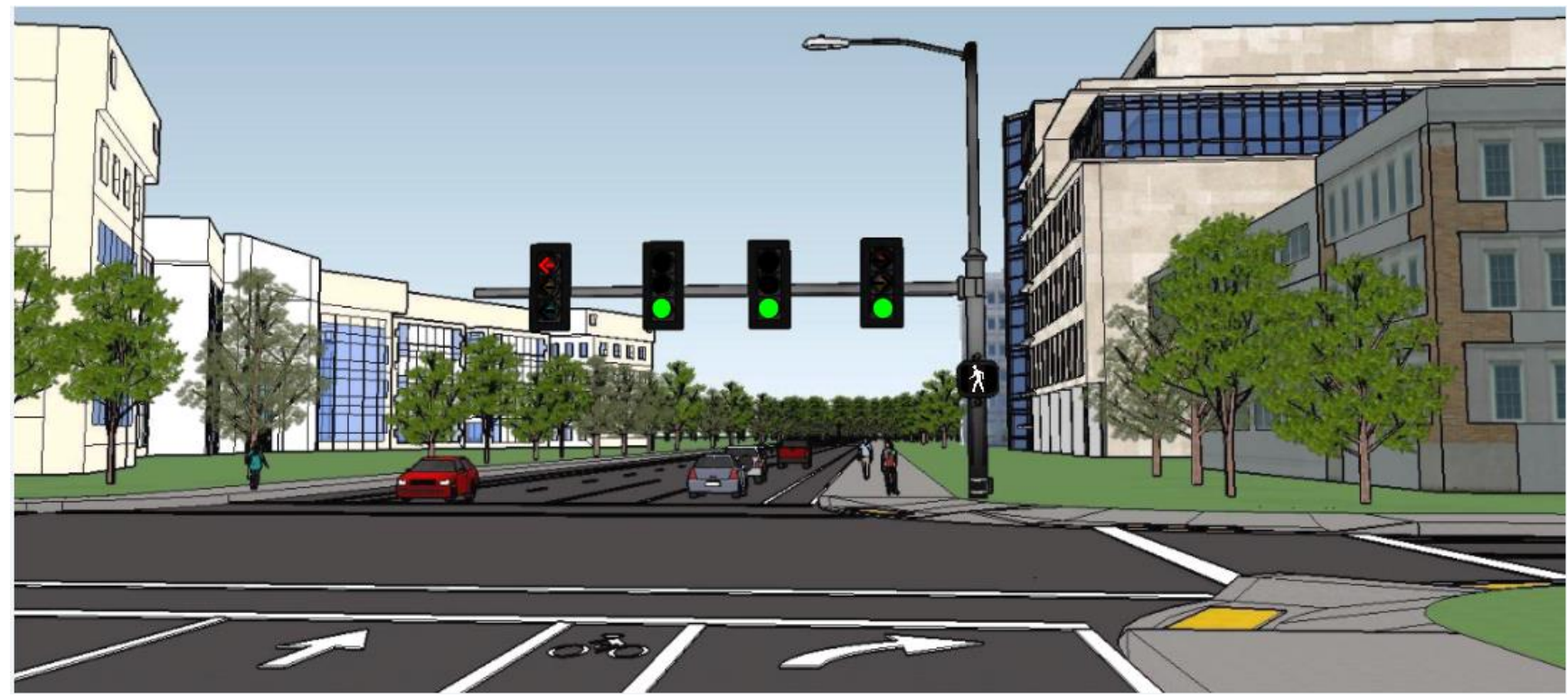

489 Figure 1. a) Steady Green Circular Ball Question Image (without Right Turn Only Sign)

490 Source: Hurwitz et al 2018

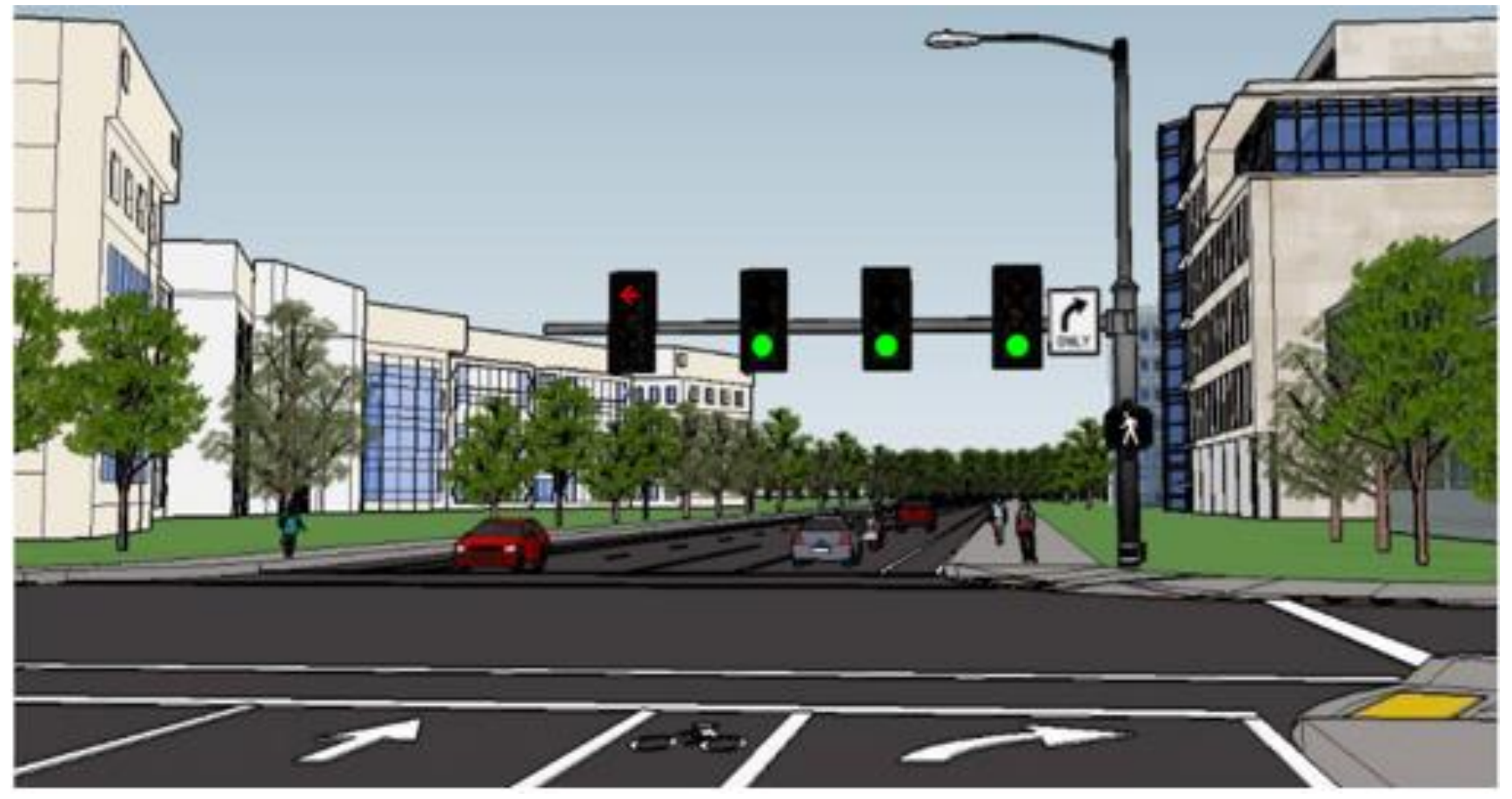

492 Figure 1. b) Steady Green Circular Ball Question Image (with Right Turn Only Sign)

493 Source: Hurwitz et al 2018 


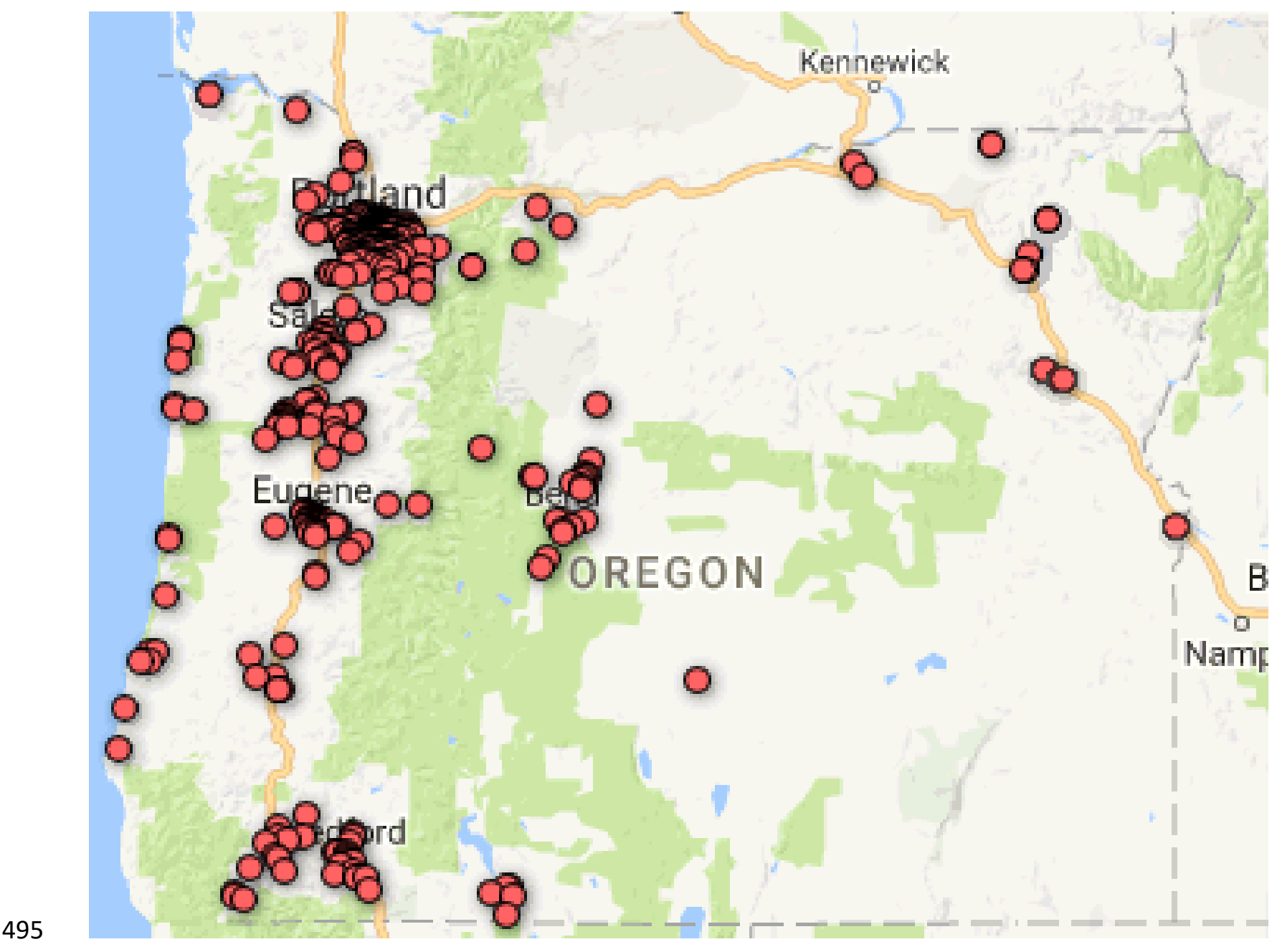

496 Figure 2. Geographic Distribution of Respondents

497 Source: Hurwitz et al 2018 


\begin{tabular}{|c|c|}
\hline Study & Objective \\
\hline $\begin{array}{l}\text { Asante and } \\
\text { Williams, } \\
1993\end{array}$ & $\begin{array}{l}\text { Evaluated simultaneous use of } \\
\text { green arrow indication with CG or } \\
\mathrm{CR} \text { in the five-section PPLT } \\
\text { display. }\end{array}$ \\
\hline $\begin{array}{l}\text { Bonneson, } \\
1993\end{array}$ & $\begin{array}{l}\text { Evaluated driver comprehension } \\
\text { of protected and permitted signal } \\
\text { indication in the five-section } \\
\text { horizontal, vertical and cluster } \\
\text { display for PPLT signal displays } \\
\text { in Nebraska. }\end{array}$ \\
\hline
\end{tabular}

Noyce and Evaluated driver understanding of Kacir, 2001 protected and PPLT displays including simultaneous GA and $\mathrm{CR}$ or $\mathrm{CG}$ indications and those with green arrow indications only as part of NCHRP 493

\section{Methodology}

- Field studies were conducted at more than 100 sites.

- Surveys were mailed to 6,000 Texas returned. residents and 902 surveys were

\section{Key Findings}

- 80\% of Texas drivers correctly understood the GA protected indication when presented in a five-section horizontal display.

- Higher comprehension rates when only the GA was displayed compared to when both GA and CG were displayed.

- Recommended against using simultaneous displays of GA and CR indications in a five-section PPLT display.

- Surveys with 115 responses received for each display/indication combination.

- GA indication in the five-section cluster display had the highest level of driver understanding.

- GA with the CG indication in a five-section horizontal display had a higher level of driver understanding.

- Comprehension rates were lower by $10 \%$ when the protected indication with simultaneous indication was shown.

- Computer-based driver survey that was completed by 2,465 drivers at eight locations.

- A total of 73,950 survey responses were received pertaining to 200 different survey scenarios.

- Simultaneous display of the CA and CR indications in a five-section PPLT signal display during a protected leftturn phase significantly reduced driver comprehension and increased driver error.

- Simultaneous display of the GA and CG indications also reduced driver comprehension when compared to the green arrow only indication, although the differences were not statistically significant.

- Drivers over the age of 65 had lower comprehension rates.

Drakopoulos Evaluated driver comprehension and Lyles, of left-turn signals.

2001

Brehmer et al. Evaluated driver comprehension 2003 of static PPLT signal displays following driver simulator experiments as part of NCHRP 493.
- Static survey of 191 respondents using slides.

- Comprehension was found to deteriorate with age.

- Flashing signals were not well understood.

- Six static computer-based evaluations of 436 drivers for twelve PPLT signal displays using either five-section cluster, fivesection vertical or four-section vertical displays were conducted.
- Overall, driver comprehension was high (83\%).

- Permissive indication comprising of both FYA and CG/FYA simultaneous indication had significantly more correct responses than displays with $\mathrm{CG}$ indication only. 


\begin{tabular}{|c|c|c|c|}
\hline Study & Objective & Methodology & Key Findings \\
\hline & & & $\begin{array}{l}\text { - Displays with CG had higher fail-critical responses than } \\
\text { displays with either FYA or CG/FYA permissive } \\
\text { indications. } \\
\text { - Statistically significant differences in comprehension rates } \\
\text { were also observed with respect to age, education, and } \\
\text { driving experience. }\end{array}$ \\
\hline $\begin{array}{l}\text { Noyce and } \\
\text { Smith, } 2003\end{array}$ & $\begin{array}{l}\text { Evaluated driver comprehension } \\
\text { and response to combinations of } \\
\text { five-section PPLT signal displays } \\
\text { (horizontal, cluster, and vertical) } \\
\text { and permissive left-turn } \\
\text { indications (CG, flashing CR, } \\
\text { flashing CY, FYA, flashing RA } \\
\text { indications in five-section signal } \\
\text { displays }\end{array}$ & $\begin{array}{l}\text { - Driving simulator experiment } \\
\text { followed by a computer-based } \\
\text { static survey. } \\
\text { - Thirty-four drivers were presented } \\
\text { with } 15 \text { PPLT signal displays on a } \\
\text { computer. }\end{array}$ & $\begin{array}{l}\text { - Type of five-section PPLT signal arrangement has little } \\
\text { effect on driver comprehension of the permissive left-turn } \\
\text { operation. } \\
\text { - Type of permissive indication used in the five-section } \\
\text { PPLT display had significant effect on driver } \\
\text { comprehension. } \\
\text { - CG, FYC, and FYA had higher comprehension rates. } \\
\text { - Five-section horizontal arrangement with FYA had the } \\
\text { highest level of driver comprehension. }\end{array}$ \\
\hline $\begin{array}{l}\text { Knodler et al. } \\
2005\end{array}$ & $\begin{array}{l}\text { Evaluated driver comprehension } \\
\text { and behavior with an FYA } \\
\text { permissive indication when they } \\
\text { appear simultaneously with } \\
\text { another indication in the same } \\
\text { signal display }\end{array}$ & $\begin{array}{l}\text { - Driving simulator experiment } \\
\text { followed by a computer-based } \\
\text { static survey and an independent } \\
\text { static survey of } 264 \text { respondents. }\end{array}$ & $\begin{array}{l}\text { - Four-section vertical signal display for FYA was } \\
\text { preferred. } \\
\text { - Retrofit of the five-section cluster display did not impact } \\
\text { comprehension rates. }\end{array}$ \\
\hline $\begin{array}{l}\text { Knodler et al. } \\
\text { 2006a }\end{array}$ & $\begin{array}{l}\text { Evaluated impact of FYA on } \\
\text { pedestrians including driver } \\
\text { comprehension of the need to } \\
\text { yield to pedestrians and } \\
\text { pedestrians recognition of } \\
\text { crossing opportunities }\end{array}$ & $\begin{array}{l}\text { - Driving simulator experiment } \\
\text { followed by a computer-based } \\
\text { static survey and an independent } \\
\text { static survey of } 139 \text { respondents. }\end{array}$ & $\begin{array}{l}\text { - Higher comprehension regarding yielding to pedestrians } \\
\text { was observed in the static environment than the simulator. } \\
\text { - CG permissive indication was associated with a higher } \\
\text { number of "GO" responses, while FYA was associated } \\
\text { with a higher number of "YIELD" responses at T- } \\
\text { intersections. }\end{array}$ \\
\hline $\begin{array}{l}\text { Knodler et al. } \\
\text { 2006b }\end{array}$ & $\begin{array}{l}\text { Evaluated driver comprehension } \\
\text { of FYA permissive indications } \\
\text { compared with FRA indication at } \\
\text { locations with wide medians }\end{array}$ & $\begin{array}{l}\text { - Driving simulator experiment } \\
\text { followed by a computer-based } \\
\text { static survey and an independent } \\
\text { static survey of } 264 \text { drivers. }\end{array}$ & $\begin{array}{l}\text { - FYA indication was associated with a high level of driver } \\
\text { comprehension. } \\
\text { - Compared to FYA, FRA resulted in significantly fewer } \\
\text { fail-critical errors at intersections with wide medians. }\end{array}$ \\
\hline $\begin{array}{l}\text { Knodler et al. } \\
2007\end{array}$ & $\begin{array}{l}\text { Quantified the impact of solid } \\
\text { yellow arrow (SYA) resulting } \\
\text { from exposure to FYA on driver } \\
\text { comprehension }\end{array}$ & $\begin{array}{l}\text { - A computer-based survey of } 212 \\
\text { drivers conducted both pre and post } \\
\text { training. }\end{array}$ & $\begin{array}{l}\text { - No evidence to suggest that FYA negatively affects the } \\
\text { driver's understanding of the SYA. }\end{array}$ \\
\hline
\end{tabular}




\begin{tabular}{|c|c|c|c|}
\hline Study & Objective & Methodology & Key Findings \\
\hline & & & $\begin{array}{l}\text { - Differences between responses pre and post training were } \\
\text { not fail-critical. }\end{array}$ \\
\hline $\begin{array}{l}\text { Henery and } \\
\text { Geyer } 2008\end{array}$ & $\begin{array}{l}\text { Evaluated driver comprehension } \\
\text { of FYA indication using four and } \\
\text { five-section heads }\end{array}$ & $\begin{array}{l}\text { - Computer-based survey of } 204 \\
\text { drivers consisting of questions on } \\
\text { the FYA indication and left turn } \\
\text { yield on green signal with R10-12 } \\
\text { sign }\end{array}$ & $\begin{array}{l}\text { - Driver comprehension of CG with supplemental R10-12 } \\
\text { sign higher than FYA without the sign. }\end{array}$ \\
\hline $\begin{array}{l}\text { Schlattler et al. } \\
2013\end{array}$ & $\begin{array}{l}\text { Evaluated driver comprehension } \\
\text { of FYA indications }\end{array}$ & $\begin{array}{l}\text { - Online static survey of } 363 \text { drivers } \\
\text { that included both protected and } \\
\text { permitted indications of PPLT } \\
\text { phasing. }\end{array}$ & $\begin{array}{l}\text { - High comprehension rates were found for CG and FYA } \\
\text { permissive left-turn indications. Some fail-critical } \\
\text { responses were observed with CG indication. } \\
\text { - Use of a supplemental sign (left-turn yield on flashing } \\
\text { arrow) increased driver comprehension of FYA and } \\
\text { reduced fail-critical responses. }\end{array}$ \\
\hline $\begin{array}{l}\text { Boot et al. } \\
2015\end{array}$ & $\begin{array}{l}\text { Evaluate a new flashing pedestrian } \\
\text { indicator (FPI) that alternated } \\
\text { between a yellow arrow and a } \\
\text { pedestrian symbol }\end{array}$ & $\begin{array}{l}\text { - Two online static surveys of } 45 \text { and } \\
46 \text { drivers. The first survey } \\
\text { evaluated the comprehension of the } \\
\text { flashing pedestrian indicator, and } \\
\text { the second survey evaluated drivers' } \\
\text { responses to actions when faced } \\
\text { with FPI and other signal } \\
\text { indications. }\end{array}$ & $\begin{array}{l}\text { - Drivers generally understood the meaning of FPI; however } \\
\text { confusion was observed among drivers proceeding } \\
\text { through the intersection. } \\
\text { - FPI was associated with significantly more yielding to } \\
\text { pedestrians. }\end{array}$ \\
\hline $\begin{array}{l}\text { Ryan et al. } \\
2019\end{array}$ & $\begin{array}{l}\text { Evaluate the effectiveness of FYA } \\
\text { for right turn applications }\end{array}$ & $\begin{array}{l}\text { - An online static survey consisting } \\
\text { of over } 200 \text { participants and driver } \\
\text { simulator study consisting of } 24 \\
\text { participants, }\end{array}$ & $\begin{array}{l}\text { - Drivers have a strong comprehension of the FYA } \\
\text { indication. } \\
\text { - Drivers understood that when a circular green indication } \\
\text { was paired with an FYA, they needed to yield as compared } \\
\text { to a circular green indication alone. } \\
\text { - Drivers also spent more time observing the FYA indication } \\
\text { as compared to the circular green indication. }\end{array}$ \\
\hline
\end{tabular}


Table 2. Survey Sampling Scheme and Response Rates

\begin{tabular}{|c|c|c|c|c|c|c|c|}
\hline County & Population & $\begin{array}{r}\text { Percentage } \\
\text { of } \\
\text { Population }\end{array}$ & $\begin{array}{r}\text { Number of } \\
\text { Postcards } \\
\text { Sent }\end{array}$ & Responses & $\begin{array}{r}\text { Response } \\
\text { Rate }\end{array}$ & $\begin{array}{r}\text { Percentage } \\
\text { of Sample } \\
\text { Response }\end{array}$ & $\begin{array}{r}\text { Difference } \\
\text { in } \\
\text { Percentage }\end{array}$ \\
\hline Baker & 16,425 & 0.41 & 41 & 4 & $10 \%$ & 1.0 & 0.6 \\
\hline Benton & 90,005 & 2.24 & 197 & 13 & $7 \%$ & 3.3 & 1.0 \\
\hline Clackamas & 397,385 & 9.90 & 983 & 52 & $5 \%$ & 13.0 & 3.1 \\
\hline Clatsop & 37,750 & 0.94 & 93 & 1 & $1 \%$ & 0.3 & -0.7 \\
\hline Columbia & 50,390 & 1.26 & 131 & 5 & $4 \%$ & 1.3 & 0.0 \\
\hline Coos & 62,990 & 1.57 & 151 & 5 & $3 \%$ & 1.3 & -0.3 \\
\hline Crook & 21,085 & 0.53 & 55 & - & - & - & \\
\hline Curry & 22,470 & 0.56 & 55 & 1 & $2 \%$ & 0.3 & -0.3 \\
\hline Deschutes & 170,740 & 4.25 & 422 & 17 & $4 \%$ & 4.3 & 0.0 \\
\hline Douglas & 109,910 & 2.74 & 273 & 8 & $3 \%$ & 2.0 & -0.7 \\
\hline Gilliam & 1,975 & 0.05 & 4 & - & - & - & \\
\hline Grant & 7,430 & 0.19 & 18 & - & - & - & \\
\hline Harney & 7,295 & 0.18 & 17 & - & - & - & \\
\hline Hood River & 24,245 & 0.60 & 59 & 2 & $3 \%$ & 0.5 & -0.1 \\
\hline Jackson & 210,975 & 5.26 & 512 & 20 & $4 \%$ & 5.0 & -0.2 \\
\hline Jefferson & 22,445 & 0.56 & 52 & 2 & $4 \%$ & 0.5 & -0.1 \\
\hline Josephine & 83,720 & 2.09 & 211 & 11 & $5 \%$ & 2.8 & 0.7 \\
\hline Klamath & 67,110 & 1.67 & 161 & 5 & $3 \%$ & 1.3 & -0.4 \\
\hline Lake & 8,010 & 0.20 & 20 & 1 & $5 \%$ & 0.3 & 0.1 \\
\hline Lane & 362,150 & 9.02 & 893 & 41 & $5 \%$ & 10.3 & 1.3 \\
\hline Lincoln & 47,225 & 1.18 & 116 & 7 & $6 \%$ & 1.8 & 0.6 \\
\hline Linn & 120,860 & 3.01 & 321 & 12 & $4 \%$ & 3.0 & 0.0 \\
\hline Malheur & 31,480 & 0.78 & 73 & 1 & $1 \%$ & 0.3 & -0.5 \\
\hline Marion & 329,770 & 8.22 & 811 & 20 & $2 \%$ & 5.0 & -3.2 \\
\hline Morrow & 11,630 & 0.29 & 30 & - & - & - & \\
\hline Multnomah & 777,490 & 19.37 & 1885 & 108 & $6 \%$ & 27.1 & 7.7 \\
\hline Polk & 78,570 & 1.96 & 188 & 5 & $3 \%$ & 1.3 & -0.7 \\
\hline Sherman & 1,790 & 0.04 & 4 & - & - & - & \\
\hline Tillamook & 25,690 & 0.64 & 64 & - & - & - & \\
\hline Umatilla & 79,155 & 1.97 & 194 & 4 & $2 \%$ & 1.0 & -1.0 \\
\hline Union & 26,625 & 0.66 & 65 & 5 & $8 \%$ & 1.3 & 0.6 \\
\hline Wallowa & 7,100 & 0.18 & 18 & - & - & - & \\
\hline Wasco & 26,370 & 0.66 & 66 & 1 & $2 \%$ & 0.3 & -0.4 \\
\hline Washington & 570,510 & 14.21 & 1425 & 41 & $3 \%$ & 10.3 & -3.9 \\
\hline Wheeler & 1,445 & 0.04 & 4 & - & - & - & \\
\hline Yamhill & 103,630 & 2.58 & 262 & 7 & $3 \%$ & 1.8 & -0.8 \\
\hline Total & $4,013,845$ & 100.0 & 9,874 & 399 & $4 \%$ & 100.0 & \\
\hline
\end{tabular}


Table 3. Demographic Comparison between Survey and Census

\begin{tabular}{|c|c|c|c|c|}
\hline Category & Demographic Variable & $\begin{array}{c}\text { Survey } \\
\text { Percentage }\end{array}$ & $\begin{array}{c}\text { Census } \\
\text { Percentage }\end{array}$ & Difference \\
\hline \multirow{2}{*}{$\begin{array}{l}\text { Gender } \\
(\mathrm{n}=397)\end{array}$} & Male & 60.7 & 49.2 & 11.5 \\
\hline & Female & 39.3 & 50.8 & -11.5 \\
\hline \multirow{6}{*}{$\begin{array}{l}\text { Age } \\
(n=399)\end{array}$} & $18-24$ & 2.0 & $*$ & \\
\hline & $25-34$ & 8.3 & 13.7 & -5.4 \\
\hline & $35-44$ & 15.3 & 13.1 & 2.2 \\
\hline & $45-54$ & 14.5 & 14.1 & 0.4 \\
\hline & $55-64$ & 29.3 & 13.3 & 16.0 \\
\hline & $65+$ & 30.6 & 13.8 & 16.8 \\
\hline \multirow{6}{*}{$\begin{array}{l}\text { Race } \\
(\mathrm{n}=375)\end{array}$} & American Indian or Alaska Native & 0.5 & 1.1 & -0.6 \\
\hline & Asian & 2.1 & 3.6 & -1.5 \\
\hline & Black or African American & 0.5 & 1.7 & -1.2 \\
\hline & Hispanic or Latino/a & 2.4 & 11.7 & -9.3 \\
\hline & White or Caucasian & 92.5 & 78.5 & 14.0 \\
\hline & Other & 1.9 & 3.3 & -1.4 \\
\hline \multirow{7}{*}{$\begin{array}{l}\text { Income } \\
(\mathrm{n}=336)\end{array}$} & Less than $\$ 25,000$ & 9.2 & 23.6 & -14.4 \\
\hline & $\$ 25,000-\$ 50,000$ & 19.2 & 23.2 & -4 \\
\hline & $\$ 50,000-\$ 75,000$ & 21.4 & 17.0 & 4.4 \\
\hline & $\$ 75,000-\$ 100,000$ & 21.1 & 11.5 & 9.6 \\
\hline & $\$ 100,000-\$ 150,000$ & 19.6 & 13.4 & 6.2 \\
\hline & $\$ 150,000-\$ 200,000$ & 6.3 & 5.7 & 0.6 \\
\hline & $\$ 200,000$ or more & 3.3 & 5.6 & -2.3 \\
\hline \multirow{10}{*}{$\begin{array}{l}\text { Education } \\
(\mathrm{n}=380)\end{array}$} & No schooling, or less than 1 year & 0.0 & & \\
\hline & Kindergarten, elementary grades $(1-8)$ & 0.0 & 4.1 & -4.1 \\
\hline & High school (grades 9-12, no degree) & 2.0 & 6.5 & -4.5 \\
\hline & High school graduate (or equivalent) & 6.1 & 24.5 & -18.4 \\
\hline & Some college (1-4 years, no degree) & 19.5 & 26.6 & -7.1 \\
\hline & Associate degree & 11.6 & 8.2 & 3.4 \\
\hline & Bachelor's degree & 34.7 & 18.9 & 15.8 \\
\hline & Master's degree & 20.3 & & \\
\hline & Professional school degree & 5.0 & 11.2 & 19.1 \\
\hline & Doctorate degree & 5.0 & & \\
\hline
\end{tabular}


Table 4. Sample Characteristics

\begin{tabular}{llc}
\hline Category & Demographic Variable & Survey \% \\
\hline \multirow{4}{*}{ Driving Frequency } & Less than 1 time per week & 2.0 \\
& 1 time per week & 0.8 \\
& $2-4$ times per week & 15.0 \\
& $5-10$ times per week & 32.1 \\
& More than 10 times per week & 50.1 \\
\hline \multirow{5}{*}{ Driver's License } & $1-2$ years & 0.5 \\
& $3-5$ years & 1.5 \\
& $6-10$ years & 2.3 \\
& $10+$ years & 95.7 \\
\hline \multirow{3}{*}{ Miles Driven per Year } & Less than 5,000 & 14.3 \\
& $5,000-9,999$ & 27.8 \\
& $10,000-14,999$ & 30.3 \\
& $15,000-19,999$ & 16.8 \\
\hline \multirow{2}{*}{ Oregon Driver's License } & Greater than 20,000 & 10.8 \\
\hline \multirow{2}{*}{ Color Blind } & Yes & 97.7 \\
& No & 2.3 \\
\hline \multirow{2}{*}{ Corrective Glasses or Contacts } & Yes & 2.5 \\
& No & 96.5 \\
& Don't want to provide this information/Don't Know & 1.0 \\
\hline
\end{tabular}

508 
Table. 5. Error Coding of Narrative

\begin{tabular}{|c|c|c|c|}
\hline Display Indication & Correct & Partially Correct & Incorrect \\
\hline Circular Green & $\begin{array}{l}\text { Turn right with caution } \\
\text { after yielding to } \\
\text { pedestrians in the } \\
\text { crosswalk }\end{array}$ & $\begin{array}{l}\text { Turn right without } \\
\text { stopping but failed to } \\
\text { state that they would } \\
\text { yield to pedestrians if } \\
\text { present in the crosswalk }\end{array}$ & Stop before turning \\
\hline Green Arrow & $\begin{array}{l}\text { Turn right without } \\
\text { stopping recognizing } \\
\text { that the steady green } \\
\text { arrow indication means } \\
\text { a protected movement } \\
\text { (or) } \\
\text { Indicated that they } \\
\text { would watch for } \\
\text { pedestrians who may } \\
\text { cross against the } \\
\text { pedestrian Don't Walk } \\
\text { signal }\end{array}$ & $\begin{array}{l}\text { Check for pedestrians } \\
\text { and turn right } \\
\text { (or) } \\
\text { slow down and check } \\
\text { for pedestrians and } \\
\text { other cross-traffic but } \\
\text { did not recognize the } \\
\text { protected movement in } \\
\text { either case }\end{array}$ & Stop before turning \\
\hline $\begin{array}{l}\text { Circular Red and Red } \\
\text { Arrow }\end{array}$ & $\begin{array}{l}\text { Come to a complete } \\
\text { stop and complete the } \\
\text { turn when they found a } \\
\text { safe gap or remained } \\
\text { stopped if they failed to } \\
\text { find a gap }\end{array}$ & $\begin{array}{l}\text { Stop or turn right, } \\
\text { without providing } \\
\text { additional details }\end{array}$ & $\begin{array}{l}\text { Stop and remain } \\
\text { stopped until the green } \\
\text { indication }\end{array}$ \\
\hline Flashing Yellow Arrow & $\begin{array}{l}\text { Turn right with caution } \\
\text { after yielding to } \\
\text { pedestrians in the } \\
\text { crosswalk }\end{array}$ & $\begin{array}{l}\text { Turn right without } \\
\text { stopping or failed to } \\
\text { state that they would } \\
\text { yield to pedestrians if } \\
\text { present in the crosswalk }\end{array}$ & Stop before turning \\
\hline
\end{tabular}


512 Table 6. Cohen's Kappa Coefficient Estimated Values

\begin{tabular}{lllllll}
\hline Category & $\begin{array}{l}\text { Kappa } \\
\text { Trial 1 } \\
\text { (with) }\end{array}$ & $\begin{array}{l}\text { Kappa } \\
\text { Trial 1 } \\
\text { (without) }\end{array}$ & $\begin{array}{l}\text { Kappa } \\
\text { Trial 2 } \\
\text { (with) }\end{array}$ & $\begin{array}{l}\text { Kappa } \\
\text { Trial 2 } \\
\text { without) }\end{array}$ & $\begin{array}{c}\text { Kappa } \\
\text { Trial 3 } \\
\text { (with) }\end{array}$ & $\begin{array}{l}\text { Kappa } \\
\text { Trial 3 } \\
\text { without) }\end{array}$ \\
\hline Circular Green & 0.86 & 0.88 & 1.00 & 1.00 & & \\
Green Arrow & 0.77 & 0.65 & 0.75 & 0.74 & 1.00 & 1.00 \\
Circular Red & 0.79 & 0.84 & 1.00 & 1.00 & & \\
Red Arrow & 0.89 & 0.91 & 1.00 & 1.00 & & \\
FYA & 0.86 & 0.81 & 1.00 & 1.00 & & \\
\hline
\end{tabular}


Table 7. Percent of Comprehension by Coded Responses and Proportions Test

\begin{tabular}{|c|c|c|c|c|c|c|c|c|c|c|c|c|}
\hline \multirow{2}{*}{$\begin{array}{l}\text { Coding of } \\
\text { Response }\end{array}$} & \multicolumn{4}{|c|}{ GA } & \multicolumn{4}{|c|}{ CG } & \multicolumn{4}{|c|}{ FYA } \\
\hline & Total & with & without & $\begin{array}{c}\text { p- } \\
\text { value }\end{array}$ & Total & with & without & $\begin{array}{c}\text { p- } \\
\text { value }\end{array}$ & Total & with & without & $\begin{array}{c}\text { p- } \\
\text { value }\end{array}$ \\
\hline $\mathrm{n}$ & 397 & 195 & 202 & & 398 & 195 & 203 & & 398 & 195 & 203 & \\
\hline Incorrect & 4 & 3 & 4 & 0.47 & 2 & 2 & 2 & 0.78 & 20 & 16 & 23 & 0.11 \\
\hline $\begin{array}{c}\text { Partially } \\
\text { correct }\end{array}$ & 33 & 28 & 37 & 0.06 & 25 & 28 & 21 & 0.1 & 4 & 3 & 5 & 0.21 \\
\hline Correct & 63 & 68 & 58 & 0.03 & 73 & 69 & 76 & 0.14 & 76 & 81 & 72 & 0.05 \\
\hline \multirow{2}{*}{$\begin{array}{l}\text { Coding of } \\
\text { Response }\end{array}$} & \multicolumn{2}{|c|}{ CR } & \multicolumn{2}{|c|}{ RA } & & & & & & & & \\
\hline & Total & with & without & $\begin{array}{c}\text { p- } \\
\text { value }\end{array}$ & Total & with & without & $\begin{array}{c}\text { p- } \\
\text { value }\end{array}$ & & & & \\
\hline $\mathrm{n}$ & 398 & 195 & 203 & & 397 & 195 & 202 & & & & & \\
\hline Incorrect & 10 & 10 & 9 & 0.26 & 40 & 34 & 46 & 0.02 & & & & \\
\hline $\begin{array}{c}\text { Partially } \\
\text { correct }\end{array}$ & 7 & 9 & 5 & 0.2 & 7 & 8 & 7 & 0.77 & & & & \\
\hline Correct & 83 & 81 & 85 & 0.76 & 52 & 58 & 46 & 0.01 & & & & \\
\hline
\end{tabular}

515

516 Note: percentage responses rounded to the nearest integer for table, may not sum to $100 \%$ 
518 Table 8: Definitions and summary statistics of significant variables in final models

\begin{tabular}{llll}
\hline Variable & Description & Mean & $\begin{array}{c}\text { Standard } \\
\text { Deviation }\end{array}$ \\
\hline DLYR & $\begin{array}{l}\text { Years of holding driver's license } \\
(0=\text { less than 10 years, } 1=\text { More than } 10 \text { yrs })\end{array}$ & 0.95 & 0.20 \\
Miles & $\begin{array}{l}\text { Miles driven per year } \\
\text { Low: }(1=\text { less than } 10,000 \text { miles, } 0=\text { Otherwise })\end{array}$ & 0.42 & 0.49 \\
ORDL & Holding Oregon driving license $(1=$ yes, $0=$ otherwise $)$ & 0.97 & 0.14 \\
Gender & Gender $(1=$ Male, $0=$ Female $)$ & 0.60 & 0.49 \\
RTO & Signs $(1=$ with, $0=$ without $)$ & 0.49 & 0.50 \\
Education & Education & 0.07 & 0.26 \\
Age & HS: $(1=$ High school graduate or equivalent, $0=$ Otherwise $)$ & 55.22 & 14.36 \\
\hline
\end{tabular}


Table 9: Parameter estimates of the logistic regression model for correct/incorrect response

\begin{tabular}{|c|c|c|c|c|c|c|c|c|c|c|}
\hline \multirow[b]{2}{*}{ Variables } & \multicolumn{2}{|c|}{ GA } & \multicolumn{2}{|c|}{ CG } & \multicolumn{2}{|c|}{ FYA $_{R T}$} & \multicolumn{2}{|c|}{ CR } & \multicolumn{2}{|c|}{ RA } \\
\hline & $\begin{array}{l}\text { Coef } \\
(\text { OR }) \\
\end{array}$ & $\begin{array}{c}\text { Z- } \\
\text { Value }\end{array}$ & $\begin{array}{l}\text { Coef } \\
(\mathrm{OR}) \\
\end{array}$ & Z-Value & $\begin{array}{l}\text { Coef } \\
(\text { OR }) \\
\end{array}$ & Z-Value & $\begin{array}{l}\text { Coef } \\
(\mathrm{OR}) \\
\end{array}$ & Z-Value & $\begin{array}{l}\text { Coef } \\
(\text { OR }) \\
\end{array}$ & Z-Value \\
\hline Constant & 4.62 & 3.43 & 3.48 & 2.69 & 0.25 & 0.27 & 3.54 & 4.64 & 0.45 & 1.03 \\
\hline Age & $\begin{array}{l}-0.07 \\
(\mathbf{0 . 9 3})\end{array}$ & -3.14 & $\begin{array}{l}-0.03 \\
(\mathbf{0 . 9 7})\end{array}$ & -1.21 & $\begin{array}{l}-0.02 \\
(\mathbf{0 . 9 8})\end{array}$ & -1.95 & $\begin{array}{l}-0.01 \\
(\mathbf{0 . 9 8})\end{array}$ & -1.20 & $\begin{array}{l}-0.01 \\
(\mathbf{0 . 9 9})\end{array}$ & -1.09 \\
\hline Gender & - & - & - & - & $\begin{array}{c}0.62 \\
\mathbf{( 1 . 8 7 )}\end{array}$ & 2.35 & - & - & - & - \\
\hline Signs & - & - & - & - & $\begin{array}{c}0.46 \\
\mathbf{( 1 . 5 9 )}\end{array}$ & 1.73 & - & - & $\begin{array}{c}0.51 \\
\mathbf{( 1 . 6 7 )}\end{array}$ & 2.41 \\
\hline $\begin{array}{l}\text { OR Driver's } \\
\text { License }\end{array}$ & - & - & - & - & $\begin{array}{c}1.68 \\
(\mathbf{5 . 3 9})\end{array}$ & 2.11 & - & - & - & - \\
\hline $\begin{array}{l}\text { High School } \\
\text { Education }\end{array}$ & $\begin{array}{l}-1.21 \\
(\mathbf{0 . 3 0})\end{array}$ & -1.80 & $\begin{array}{l}-1.97 \\
(\mathbf{0 . 1 4})\end{array}$ & -2.53 & $\begin{array}{l}-0.57 \\
(\mathbf{0 . 5 6})\end{array}$ & -1.26 & $\begin{array}{l}-0.98 \\
(\mathbf{0 . 3 7})\end{array}$ & -1.94 & - & - \\
\hline Low Annual Miles & - & - & - & - & - & - & $\begin{array}{l}-0.87 \\
(\mathbf{0 . 4 2})\end{array}$ & -2.47 & - & - \\
\hline $\begin{array}{c}\text { Years of Driver's } \\
\text { License }\end{array}$ & $\begin{array}{c}2.99 \\
(\mathbf{1 9 . 9 3})\end{array}$ & 2.72 & $\begin{array}{c}2.39 \\
\mathbf{( 1 0 . 9 2 )}\end{array}$ & 2.11 & - & - & - & - & - & - \\
\hline \multicolumn{11}{|l|}{ Model Summary } \\
\hline $\begin{array}{c}\text { Number of } \\
\text { Observations }\end{array}$ & \multicolumn{2}{|c|}{267} & \multicolumn{2}{|c|}{298} & \multicolumn{2}{|c|}{377} & \multicolumn{2}{|c|}{367} & \multicolumn{2}{|c|}{368} \\
\hline $\begin{array}{c}\text { Deviance Test } \\
\text { (P-value) }\end{array}$ & \multicolumn{2}{|c|}{0.99} & \multicolumn{2}{|c|}{0.99} & \multicolumn{2}{|c|}{0.59} & \multicolumn{2}{|c|}{0.99} & \multicolumn{2}{|c|}{$<0.001$} \\
\hline $\begin{array}{c}\text { Pearson Test } \\
\text { (P-value) } \\
\text { Hosmer- }\end{array}$ & \multicolumn{2}{|c|}{0.16} & \multicolumn{2}{|c|}{0.16} & \multicolumn{2}{|c|}{0.37} & \multicolumn{2}{|c|}{0.48} & \multicolumn{2}{|c|}{0.47} \\
\hline $\begin{array}{l}\text { Lemeshow Test } \\
\text { (P-value) }\end{array}$ & \multicolumn{2}{|c|}{0.10} & \multicolumn{2}{|c|}{0.24} & \multicolumn{2}{|c|}{0.52} & \multicolumn{2}{|c|}{0.30} & \multicolumn{2}{|c|}{0.96} \\
\hline
\end{tabular}

